TEACHING AND LEARNING ETHICS

\title{
Sex and the surgery: students' attitudes and potential behaviour as they pass through a modern medical curriculum
}

\author{
J Goldie, L Schwartz, J Morrison
}

J Med Ethics 2004;30:480-486. doi: 10.1136/jme.2003.006304

See end of article for authors' affiliations

Correspondence to:

Correspondence to:
Dr J Goldie, Department of General Practice,

University of Glasgow, 4

Lancaster Crescent,

Glasgow, G12 ORR, UK;

johngoldie@fsmail.net

Received 20 August 2003

In revised form

23 November 2003

Accepted for publication

29 November 2003
Objective: To examine students' attitudes and potential behaviour to a possible intimate relationship with a patient as they pass through a modern medical curriculum.

Design: A cohort study of students entering Glasgow University's new learner centred, integrated medical curriculum in October 1996.

Methods: Students' pre year 1 and post year 1, post year 3, and post year 5 responses to the "attractive patient" vignette of the Ethics in Health Care Survey instrument were examined quantitatively and qualitatively. Analysis of students' multi-choice answers enabled measurement of the movement towards professional consensus opinion. Analysis of written justifications helped determine whether their reasoning was consistent with professional consensus and enabled measurement of change in knowledge content and recognition of the values inherent in the vignette. Themes on students' reasoning behind their decision to enter a relationship or not were also identified.

Results: No significant movement towards consensus was found at any point in the curriculum. There was little improvement in students' performance in terms of knowledge content and their abilities to recognise the values inherent in the vignette. In deciding to enter a relationship with the patient the most frequently used reasoning was that it could be justified if the patient changed their doctor.

Conclusions: Teaching on the subject of sexual or improper relationships between doctors and patients, including relationships with former patients requires to be made explicit. Case based teaching would fit in with the ethos of the problem based, integrated medical curriculum.
S exual or improper emotional relationships between a doctor and a current patient are prohibited by all codes of ethics set up by medical professional bodies. ${ }^{1}$ Sexual relationships between doctors and their patients can have devastating consequences for the patients ${ }^{2}$ and can harm doctors' abilities to make objective medical judgements. ${ }^{3}$ In the UK, the General Medical Council (GMC) advises doctors: "You must not allow your personal relationships to undermine the trust which patients place in you. In particular, you must not use your professional position to establish or pursue a sexual or improper emotional relationship with a patient or someone close to them". ${ }^{4}$

However, sexual relationships between doctors and patients occur. Searight and Campbell estimated 11\% of family physicians in the USA have had sexual contact with at least one patient. ${ }^{5}$ Thomson and White's survey of Australian general practitioners found $32 \%$ personally knew of a colleague who had engaged in sexual contact with a patient. ${ }^{6}$ Lamont and Woodward's survey of Canadian gynaecologists found $10 \%$ admitted knowing of a colleague who had been sexually involved with a patient. In the same survey $3 \%$ of male and $1 \%$ of female gynaecologists reported sexual involvement with a patient. ${ }^{7}$ Ovens and Permaul-Woods's survey of Canadian emergency physicians found $8.7 \%$ were aware of a colleague who had been sexually involved with a patient, or former patient, with $6.2 \%$ admitting to having sexual involvement with a former patient. ${ }^{8}$ In the USA, Bayer et al's nationwide survey of 1600 doctors, from various specialties, found $4.5 \%$ of respondents admitted to dating a patient, with $3.4 \%$ admitting having sexual contact with a patient. $^{9}$

The numbers of doctors disciplined for sexual offences with patients is considerably smaller. Donaldson's survey of
49 senior doctors over a five year period found serious concerns raised about $6 \%$ of these doctors. Of these concerns $14 \%$ related to sexual matters. ${ }^{10}$ Morrison and Wickersham's study of Californian doctors ( $10 \%$ of all doctors in the USA) found $0.24 \%$ of doctors receive some form of disciplinary action by the state medical board per year, and $10 \%$ of such offences are for inappropriate contact with patients. ${ }^{11}$ Dehlendorf and Wolfe's analysis of sex related orders during the period 1981-96, drawing figures from a national database of disciplinary orders taken by state medical boards and federal agencies in the USA, found disciplinary action against physicians for sex related offences to be increasing over time. In the year with the highest rate of offences, $0.02 \%$ of all US physicians were disciplined for sex related offences. ${ }^{2}$

Psychiatrists, gynaecologists, and general practitioners are significantly more likely to offend than those in other specialties. $^{21213}$ Particularly vulnerable are socially isolated, middle aged men experiencing a mid-life crisis, ${ }^{14}$ who are eminent in their field. ${ }^{15}$ The risk of sexual misconduct increases with age ${ }^{2}$ by a risk ratio of 1.44 with every decade. ${ }^{12}$ Marital discord, loss of important relationships, and a professional crisis in the offenders' lives often are trigger factors. ${ }^{16}$

Traditional medical education has inadequately tackled this issue. Gartrell et al found 56\% of doctors reported having had no education on doctor-patient sexual contact during their medical degree, and only 3\% had undertaken training on this issue after graduation. ${ }^{17}$ The University of Glasgow introduced a new learner centred, integrated medical curriculum in 1996 which has medical ethics and law as one of the vertical themes running throughout the five year course. This provided an opportunity to study longitudinally the effect of ethics teaching on students' potential behaviour 
on facing ethical dilemmas. The present study aimed to examine students' attitudes and potential behaviour to a possible improper relationship with a patient as they progressed through the curriculum.

\section{METHOD}

A cohort design was adopted.

\section{Subjects}

A cohort of 162 students from the first intake of Glasgow's new curriculum took part in the study.

\section{Instrument}

The adapted Ethics in Health Care Survey Instrument (EHCI) was used. The EHCI consists of 12 case vignettes, which include an ethical dimension. In addition to asking subjects to choose one of the pre-set answers to each case vignette, the EHCI also asks them to justify their chosen response. ${ }^{18-20}$ For the purpose of this study only the responses to vignette 9 (box 1) were considered.

In October 1996, the EHCI was distributed to the 238 students entering the new curriculum. There was no compulsion for students to undertake the questionnaire; their participation was entirely voluntary. The students were assured of this and of the confidentiality and anonymity of their responses. A consent form was attached to the instrument. A total of 162 patients returned a completed EHCI pre year 1 forming the cohort under observation.

Ethics teaching is mainly delivered in the first three years of the curriculum as part of the Vocational Studies course. The main teaching format in Vocational Studies is small group teaching led by a generalist clinical tutor. The content of Vocational Studies ethics sessions has been previously described.$^{18-20}$ The EHCI was distributed to the cohort at the end of year 1, the year in which the largest proportion of ethics sessions take place, and at the end of year 3 following completion of Vocational Studies.

After year 3, 101 students left the curriculum to undertake an intercalated BSc, of whom 67 were from the study cohort. The remaining students entered the predominantly clinical years of the curriculum where the emphasis in ethics teaching is on preparation for professional life, including working with others and critical case analysis. ${ }^{20}$ The EHCI

\section{Box 1: Ethics in Health Care Survey Instrument Question 9: the attractive patient}

You have just taken over a single handed practice on a remote, small Scottish island. You have always wanted a rural practice, and hope someday to marry and raise children on the island. Lee Cuthbert is an attractive, intelligent, level headed patient whose family has lived on the island for generations. Lee is also a member of the bird watching club you have joined. You have been treating Lee for some time for a difficult and unpleasant skin condition, which appears to be clearing up. Although surgery visits will continue to be necessary for monitoring, the patient is substantially improved.

At the end of a visit, Lee smiles warmly and invites you for dinner, clearly evidencing an interest in being more than your patient. Your options are:

- Accept the invitation.

- Do not accept the invitation.

Please state the reasons for your choice:

\section{Box 2: Classification of responses}

\section{- Consensus responses}

- Category 1 Based on the consensus reasoning of experts in the field of medical ethics, legal requirements on practitioners, or on policies issued by relevant professional institutions

\section{- Subcategories of non-consensus responses}

- Category 2 Based on the subject's personal values/ morality

- Category 3 Influenced by other non-medical/legal value systems

- Category 4 Although based on moral argument, it is not consistent with the profession's normative values

- Category 5 Indeterminate

was distributed to cohort students who were in the process of completing year 5, the final year of the medical curriculum.

Students' pre-set responses to the consensus questions in each questionnaire were tabulated in an Excel spreadsheet. The written responses to each vignette were transcribed and added to the database.

\section{Analysis}

The students' multi-choice responses to vignette 9 were compared at the four time points to determine if their views were consistent with the consensus judgement of informed professionals pre-curriculum and if they changed as they progressed through the curriculum.

The students' written justifications of their pre-set answer were classified independently by the researchers (JG and JM). They were initially classified as being either a "professional consensus" or an "other" response, a form of data reduction after Huberman and Miles. ${ }^{21}$ A professional consensus response was considered to be one based on the consensus reasoning of experts in the field of medical ethics, legal requirements on practitioners, or on policies issued by relevant professional institutions. The "other" response category was subclassified (box 2). These categories were derived from the reflections of the Glasgow researchers ( $\mathrm{JG}$,

\section{Box 3: Hierarchy of subjects' action justifications}

- Level 3

The subject, in proposing a course of action, not only demonstrates the ability to identify, classify, and analyse the issue(s) involved, but also demonstrates the ability to consider alternatives when deciding his or her course of action

- Level 2

The subject, in proposing a course of action, demonstrates his or her ability to identify, classify, and analyse one or more of the ethical issue(s) contained

\section{- Level 1}

The subject, in proposing a course of action, demonstrates that he or she is able to recognise and/or identify one or more of the ethical issue(s) contained 


\section{Box 4: Values recognition hierarchy}

- Level 4

The subject recognises the value system(s) inherent in his or her course of action, the value system(s) of the individuals involved in the decision making process and those of wider society

- Level 3

The subject recognises both the value(s) inherent in his or her course of action and those of the individual(s) involved in the decision making process

- Level 2

The subject recognises the value(s) inherent in either his or her course of action or those of the individual(s) involved in the decision making process

- Level 1

There is no recognition of the value(s) inherent in the subject's proposed course of action or those of the individual(s) involved in the decision making process

LS, JM) and one of the original developers of the instrument (Ken Kipnis, University of Hawaii), and grounded in responses given by students in both Hawaii and Glasgow. ${ }^{22} 23$

Students' written categories were also compared with their choice of pre-set answer to help determine whether their thinking was consistent with professional consensus.

Responses judged to be consensus responses were further classified on the hierarchies of subjects' action justifications and values recognition (boxes 3 and 4). The hierarchical levels were grounded in previous responses given by Glasgow students and influenced by the consensus aim of medical ethics education. During the classification process it became clear that the action justification hierarchy required to be extended due to the poor quality of a small number of

\section{Box 5: Hierarchy of subjects' action justifications}

\section{- Level 4}

The subject, in proposing a course of action, not only demonstrates the ability to identify, classify, and analyse the issue(s) involved, but also demonstrates the ability to consider alternatives when deciding his or her course of action

\section{- Level 3}

The subject, in proposing a course of action, demonstrates his or her ability to identify, classify, and analyse one or more of the ethical issue(s) contained

- Level 2

The subject, in proposing a course of action, demonstrates that he or she is able to recognise and/or identify one or more of the ethical issue(s) contained

- Level 1

The subject, in proposing a course of action, does not identify the ethical issue(s) contained in the vignette
Table 1 Kappa coefficients for the agreement between the two researchers on the categorisations and hierarchical classifications of students' written justifications on all occasions of the survey

\begin{tabular}{lllll}
\hline & $\begin{array}{l}\text { Categorisation } \\
\text { as consensus } \\
\text { or non-consensus }\end{array}$ & $\begin{array}{l}\text { Five category } \\
\text { classification }\end{array}$ & $\begin{array}{l}\text { Action } \\
\text { justification } \\
\text { hierarchy }\end{array}$ & $\begin{array}{l}\text { Values } \\
\text { recognition } \\
\text { hierarchy }\end{array}$ \\
\hline Kappa & 0.96 & 0.8 & 0.85 & 0.65 \\
\hline
\end{tabular}

responses. The change is shown in box 5. Comparison of the positions of students' justifications on the hierarchies before and after instruction was used as measures of change following instruction. ${ }^{22} 23$

The reliability of the categorisation/classification process was estimated using the kappa coefficient, which compares the level of agreement between the two raters with that which would have been expected by chance alone (table 1). The results indicated acceptable interrater reliability. Following independent rating, areas of disagreement between the raters on the categorisations and hierarchical classifications of the written responses were identified and the responses were further examined and discussed until agreement was reached.

Students' written responses were further coded independently by JG and JM to identify themes for students' reasoning behind their decision to enter in a relationship with the patient or not. Crosschecking of the researchers' themes showed a high level of agreement.

\section{RESULTS}

The EHCI post year 1 was returned by 111 cohort students and the EHCI post year 3 by 85 . The final year class contained 107 students, of whom 102 were from the original intake and 79 from the original cohort. The EHCI post year 5 was returned by 62 cohort students. All 62 respondents had provided an answer to the multi-choice question in vignette 9. There were precurriculum and postcurriculum written responses to vignette 9 from 54 students, 30 students provided written responses on four occasions and a further 10 on three occasions (figs 1 and 2). Students remaining from the original cohort were similar to the whole class in

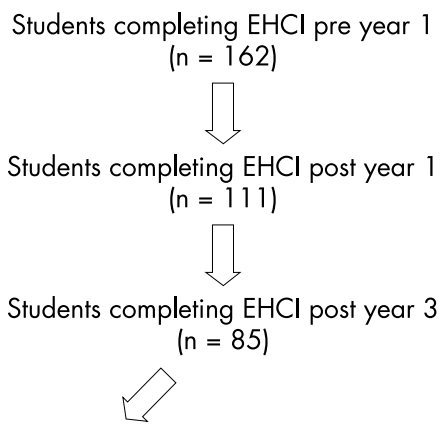

Students who previously completed an $\mathrm{EHCl}$

leaving the curriculum to undertake an

intercalated BSc

$(n=67)$

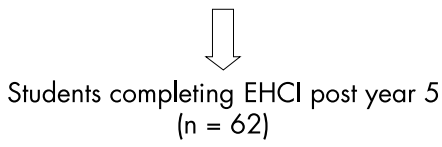

Figure 1 The number of students completing the Ethics in Health Care Survey Instrument (EHCl) at each survey point. 


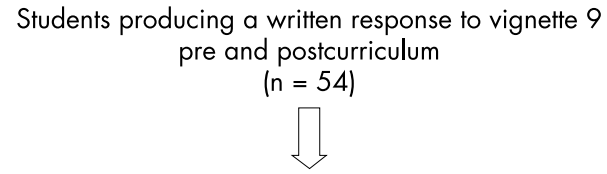

Students producing a written response to vignette 9 pre and postcurriculum and post year 1 $(n=40)$

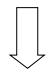

Students producing a written response to vignette 9 pre and postcurriculum, post year 1 and post year 3 ( $n=30)$

Figure 2 The number of students providing a written response to vignette 9 of the Ethics in Health Care Survey Instrument (EHCI) precurriculum and postcurriculum and at the other survey points.

terms of age (mean age of cohort students: 24 years; mean age of class 23 years 8 months), sex (male:female 1:2.5 and $1: 2$, respectively), overseas origin ( $10 \%$ and $9 \%$, respectively) and holding a previous degree(s) (8\% and $8 \%$, respectively). They were also similar to the original cohort in terms of sex (1:2.5, 1:2 original cohort), overseas origin (10\% and $9 \%$, respectively) and holding a previous degree ( $8 \%$ and 5\%, respectively).

Statistical analysis of student's choice of pre-set answer to vignette 9 showed no significant movement towards consensus at any point in the curriculum. ${ }^{20}$ By the end of the curriculum while $60 \%(n=32)$ chose the consensus multi-choice response, analysis of the written justification categorisations showed only $58 \%(n=19)$ of these students provided a consensus written justification for their choice (table 2).

The reasoning behind responses categorised as nonconsensus was most often based on moral argument not consistent with the professions' normative values. This was also the case where the reasoning behind the choice of consensus pre-set answer was not consistent with professional consensus thinking (table 3).

There was little improvement in students' performance in terms of the position of their written justifications on the hierarchies as they progressed through the curriculum (table 4). This was the case both in terms of knowledge content and their abilities to recognise the values inherent in the vignette.

Students' reasoning behind their decision to embark on a relationship or not, and the frequency of their occurrence at each survey point, is shown in table 5 . Often more than one theme was identified from a response. Where the reasoning behind the decision not to embark on a relationship was aligned with professional consensus thinking, the themes identified most frequently were that the course of action was deemed unethical and that the doctor-patient relationship would be compromised:

It is unethical for a doctor to have a relationship with a patient other than a professional one as it leaves room for exploitation.

This could be interpreted in the future, if the relationship did not work out, as an abuse of the doctor-patient relationship.

Where the reasoning behind the consensus pre-set answer was not aligned with professional consensus thinking, the most frequent reasoning used was that a relationship could be justified if the patient changed their doctor:
Table 2 Comparison of the number of consensus written justifications provided by students with the number of consensus multi-choice responses chosen for each time point

\begin{tabular}{llll}
\hline & $\begin{array}{l}\text { Consensus } \\
\text { justifications } \\
\text { provided (\%) }\end{array}$ & $\begin{array}{l}\text { Consensus multi- } \\
\text { choice response } \\
\text { chosen (\%) }\end{array}$ & $\%$ Agreement \\
\hline $\begin{array}{l}\text { Pre year 1 } \\
(n=54)\end{array}$ & $13(24)$ & $25(46)$ & 52 \\
$\begin{array}{l}\text { Post year } 1 \\
(n=40)\end{array}$ & $13(33)$ & $20(50)$ & 65 \\
$\begin{array}{l}\text { Post year } 3 \\
(n=30)\end{array}$ & $10(33)$ & $18(60)$ & 55 \\
$\begin{array}{l}\text { Post year 5 } \\
(n=54)\end{array}$ & $19(35)$ & $32(60)$ & 58 \\
\hline
\end{tabular}

Doctor-patient relationship [is one] that implies trust, confidentiality. This would not remain intact if things progressed. However, accept if he changes doctors.

Where students decided to enter into a relationship with the patient, as well as the strategy of encouraging the patient to find another doctor, the context of being the only doctor on a remote island was often used to justify the relationship:

A doctor theoretically should not have a relationship with a patient and should refer the patient to some other doctor. However, since the doctor is the only feasible one in the region, then I would accept the invitation - if the island is that small then everyone on the island is probably related anyway.

On a small Scottish island where you're the only doctor, everyone's going to be your patient. As the condition is clearing up too, I see no reason why not? If you ever hope to marry and raise kids you will probably end up with one of the islanders anyway.

Another common theme used to justify the relationship was the importance for doctors separating their private from professional lives:

$\mathrm{He}$ is not merely a patient as he attends the same club and has the same interests. As long as [your] professional and private lives are kept separate this would be OK.

\section{DISCUSSION}

Cohort studies are particularly appropriate in research on human growth and development. They provide greater opportunity to observe trends and to distinguish "real" change from chance occurrences. ${ }^{24}$ This study, like most cohort studies, suffered from sample mortality; a major factor for this was students undertaking intercalated degrees. However, the cohort students consisted of $60 \%$ of the students completing the new Glasgow medical curriculum. They were representative of the year as a whole and of the original cohort.

Cohort studies can also suffer from "control effects". This was a potential source of bias because the same instrument was used on four separate occasions. However, the time interval of one year between the first and second stages; two years between the second and third stages of the study; and a further two years between the third and fourth stages made this less likely. In addition, the students did not receive 
Table 3 The researchers' categorisation of written justifications judged not to be consistent with consensus reasoning with students' corresponding multi-choice answer at each survey point

\begin{tabular}{|c|c|c|c|c|c|}
\hline $\begin{array}{l}\text { Multi-choice } \\
\text { answer }\end{array}$ & Category & Pre year $1(\%)$ & Post year 1 (\%) & Post year 3 (\%) & Post year $5(\%)$ \\
\hline \multirow{4}{*}{ Non-consensus } & 2 (Personal values/morality) & $13(45)$ & $10(50)$ & $6(50)$ & $8(36)$ \\
\hline & 3 (Influence of other non-medical/legal value systems) & 0 & 0 & & 0 \\
\hline & 4 (Inconsistent with consensus though based on moral argument) & $15(52)$ & $9(45)$ & $6(50)$ & $14(64)$ \\
\hline & 5 (Indeterminate) & $1(3)$ & $1(5)$ & 0 & 0 \\
\hline \multirow[t]{4}{*}{ Consensus } & 2 (Personal values/morality) & $3(25)$ & $3(43)$ & $3(43)$ & $4(31)$ \\
\hline & 3 (Influence of other non-medical/legal value systems) & 0 & 0 & & 0 \\
\hline & 4 (Inconsistent with consensus though based on moral argument) & $9(75)$ & $4(57)$ & $4(57)$ & $8(62)$ \\
\hline & 5 (Indeterminate) & 0 & 0 & 0 & 1 (7) \\
\hline
\end{tabular}

feedback on the "correct" answer to vignette 9, or on how they performed individually.

Students' performance on the EHCI as a whole, in terms of movement towards consensus professional opinion, was found to improve following the first year of the curriculum. ${ }^{18-20}$ The improvement was sustained to the end of the curriculum, although no further improvement occurred. ${ }^{19}{ }^{20}$ For the individual vignettes covering professional issues, which include vignette 9, no improvement was found at any time point in the curriculum. ${ }^{18-20}$ Cohort studies can suffer from the interaction of biological, environmental, and interventional influences. In medical curricula, the longer students are exposed to the hidden curriculum and the process of "moral enculturation", the greater the risk of students' ethical development being detrimentally affected..$^{25}$ While it may partly explain the lack of improvement in the Glasgow students' performance in the vignettes covering professional issues, the relative lack of direct teaching on the issues covered in the vignettes possibly played a greater part. ${ }^{18-20}$ Gartrell et al's 1992 survey demonstrated a lack of direct teaching on the issue of sexual or improper emotional relationships with patients, which was felt to contribute to the development of improper relationships. ${ }^{17}$ The latest UK consensus statement on the core medical ethics curriculum merely recommends teaching on the "Implications for students and their relationship with patients". ${ }^{26}$ While the issue was not the subject of an individual teaching session it was covered in plenary sessions on "Oaths, codes and regulations" and "Dealing with medical mistakes" in year 3. The principle of autonomy, and its prerequisites, patient competence and informed consent, are extensively covered in year 1 where there is also a session on "Vulnerability", covering the vulnerability of both patients and doctors. Students were also provided with the GMC document Duties of a Doctor $^{27}$ on admission to the curriculum and encouraged

Table 4 The hierarchical ratings given by the researchers to written justifications judged to be based on reasoning consistent with professional consensus at each survey point

\begin{tabular}{|c|c|c|c|c|}
\hline & Pre year 1 & Post year 1 & Post year 3 & Post year 5 \\
\hline \multicolumn{5}{|c|}{ Action justification hierarchy } \\
\hline 4 & 0 & 0 & 1 & 0 \\
\hline 3 & 3 & 4 & 4 & 3 \\
\hline 2 & 7 & 8 & 3 & 15 \\
\hline 1 & 3 & 1 & 3 & 1 \\
\hline \multicolumn{5}{|c|}{ Values recognition hierarchy } \\
\hline 4 & 1 & 0 & 0 & 0 \\
\hline 3 & 2 & 1 & 0 & 0 \\
\hline 2 & 10 & 12 & 10 & 19 \\
\hline 1 & 0 & 0 & 0 & 0 \\
\hline
\end{tabular}

to refer to them throughout. Teaching on the issue may require to be more explicit if it is to impact on students' learning. Simply teaching principles, related concepts, and/or decision making templates is not always sufficient as learning often requires to be contextualised for students. ${ }^{28}$ The teaching need not be didactic, a case similar to that in vignette 9 could be used as the focus for students' exploration of the underlying issues.

Student's performance in vignette 9 was poorer than it appeared from their multi-choice responses. While $48-60 \%$ of students chose the consensus response for vignette 9 at the various time points through the curriculum, only $52-65 \%$ of these students justified their choice using reasoning based on consensus opinion. There was also no movement of responses up the action justification or values recognition hierarchies as students progressed through the curriculum. Measuring students' proposed behaviour on encountering ethical dilemmas has been the approach favoured in recent years. ${ }^{28} \mathrm{~A}$ common feature of the instruments developed has been the provision for subjects of a choice of options in deciding which action to take. While this is of value it leaves them open to the criticism that they say little about the subject's own thinking about the issues involved, or indeed whether or not they would recognise the issues. ${ }^{29}$ These findings illustrate the importance of testing students' underpinning reasoning in instruments which attempt to measure students' decision making abilities using a multi-choice format.

There are obvious problems with consensus as a method of decision, it can be parochial and not sensitive to particular features of a specific case. ${ }^{30}$ In the context of vignette 9 while it was understandable that some students held the attitude that there would be few opportunities for the doctor to meet a suitable mate on a remote island, and recognised that doctors in such communities often face dilemmas regarding keeping their personal lives separate from their professional lives, there is a clear consensus that sexual or improper emotional relationships between a doctor and a current patient are wholly prohibited. The use of consensus opinion was therefore justified.

Where students chose the consensus pre-set answer, but provided justifications which were considered non-consensus, the commonest reasoning used was that it would be acceptable to pursue the relationship if/when the patient changed doctor/became an ex-patient. The issue of sexual relationships between doctors and former patients remains an area of debate among the medical profession. The American Psychiatric Association has stated that "sexual activity with a former patient is unethical ... with no qualifications" ${ }^{31}$ The Council of Ethical and Judicial Affairs of the American Medical Association has stated "sexual or romantic relationships with former patients are unethical if the physician uses or exploits trust, knowledge, emotions, or influence derived from the previous professional relationship". ${ }^{32}$ The New Zealand Medical Council adopted a "zero 
Table 5 Students' reasons for and against accepting the dinner invitation and the frequency of their occurrence at each survey point

\begin{tabular}{|c|c|c|c|c|c|}
\hline & Pre year 1 & Post year 1 & Post year 3 & Post year 5 & Total \\
\hline \multicolumn{6}{|l|}{ Reasons given for accepting } \\
\hline How else will I meet someone? & 5 & 3 & 4 & 5 & 17 \\
\hline Professional and private lives can be separate & 4 & 3 & 5 & 7 & 19 \\
\hline When patient changes doctor/becomes an ex-patient & 9 & 3 & 2 & 4 & 18 \\
\hline How else will I meet someone? & 5 & 3 & 4 & 5 & 17 \\
\hline Everyone on the island is a patient including your wife/husband & 5 & 5 & 2 & 4 & 16 \\
\hline There's been previous social contact & 3 & 2 & $\overline{0}$ & 5 & 10 \\
\hline As long as doctor doesn't take advantage/abuse patient & 3 & 2 & 2 & 3 & 10 \\
\hline Doctors are only human & 3 & 2 & 1 & 2 & 8 \\
\hline If both consent & 1 & 1 & 1 & 1 & 4 \\
\hline Just be friends & 1 & 1 & 0 & 1 & 3 \\
\hline Patient made first move & 2 & 0 & 0 & 0 & 2 \\
\hline Life's too short & 0 & 1 & 1 & 0 & 2 \\
\hline Patient is level headed & 1 & 0 & 0 & 0 & 1 \\
\hline I see no harm & 1 & 0 & 0 & 0 & 1 \\
\hline Follow your heart & 0 & 1 & 0 & 0 & 1 \\
\hline No legal barrier & 0 & 0 & 0 & 1 & 1 \\
\hline \multicolumn{6}{|l|}{$\begin{array}{l}\text { Reasons given for not accepting } \\
\text { Professional consensus based }\end{array}$} \\
\hline Unethical & 2 & 4 & 4 & 12 & 22 \\
\hline Compromise doctor-patient relationship & 6 & 5 & 4 & 6 & 21 \\
\hline Abuse of power & 3 & 0 & 3 & 1 & 7 \\
\hline Unprofessional & 1 & 3 & 2 & 1 & 7 \\
\hline Fear of GMC consequences & 4 & 0 & $\overline{1}$ & 1 & 6 \\
\hline Breach of trust & 2 & 0 & 1 & 0 & 3 \\
\hline Breach of confidentiality & $\overline{1}$ & 1 & 1 & 0 & 3 \\
\hline Loss of respect in community & 2 & 0 & 0 & 0 & 2 \\
\hline Transference issues & 1 & 0 & 0 & 0 & 1 \\
\hline Tell patient no & 0 & 0 & 1 & 0 & 1 \\
\hline \multicolumn{6}{|l|}{ Non professional consensus based } \\
\hline When patient changes doctor/becomes an ex-patient & 7 & 3 & 5 & 9 & 24 \\
\hline Professional and private lives can be separate & 3 & 4 & 2 & 2 & 11 \\
\hline There's been previous social contact & 2 & 0 & 0 & 0 & 2 \\
\hline Wait a while & 1 & 0 & 0 & 1 & 2 \\
\hline Everyone on the island is a patient & 0 & 0 & 1 & 0 & 1 \\
\hline The skin condition would put me off & 0 & 0 & 0 & 1 & 1 \\
\hline
\end{tabular}

tolerance" policy of sexual relationships between doctors and their patients in $1994 .{ }^{33}$ Two years later a further policy statement was released which stated that whilst complaints regarding sexual relations with former patients will be considered individually, it will be presumed to be unethical if the "doctor-patient relationship involved psychotherapy, or long-term counselling and support; the patient suffered a disorder likely to impair judgement or hinder decisionmaking; the doctor knew the patient had been sexually abused in the past; or the patient was under the age of 20 when the doctor-patient relationship ended". ${ }^{34}$ This position is currently undergoing further review. In the UK, the GMC has not produced a policy statement, but like its counterpart in New Zealand its approach would be to consider each case individually from the standpoint of a critical outside observer (General Medical Council Standards Team, personal communication, May 2003). From a legal perspective the Californian courts have ruled that relationships between doctors and former patients should not take place until there has been at least a two year gap during which there has been no contact, of any sort, between the doctor and the patient. ${ }^{35}$

In considering the ethics of sexual relationships between doctors and former patients a recent review of the literature concluded that such relationships are almost always unethical due to the persistence of transference, the unequal power balance in the original doctor-patient relationship and the ethical implications arising from these factors with respect to the patient's autonomy and ability to consent. ${ }^{1}$ As mentioned previously there is little disagreement on the issue of whether a current patient can ever give his or her free consent to entering into a sexual relationship with his or her doctor. ${ }^{36} 37$
The lack of competence due to the presence of transference is the commonest and strongest basis for this claim, although Guntheil and Gabbard prefer a model of "undue influence" rather than claiming such patients are necessarily incompetent. ${ }^{36}$ Transference developing in the doctor-patient relationship is likely to persist as there is no empirical evidence to suggest that it disappears or even reduces with cessation of the doctor-patient relationship. ${ }^{38}$

However, not every doctor-patient relationship involves transference. Zelas argues "no rule of thumb regarding a suitable time period of restraint nor regarding the specific nature of the doctor-patient relationship can be offered ... a reasonable guide-line is that if the sexual attraction and desire for relationship commenced in the context of the doctor-patient relationship then it is unlikely to be wellfounded at any time in the future." However, she adds, "there seems to be widespread agreement that when a patient has been in long term psychotherapy or counselling with the doctor then an ordinary social relationship can never be established."

The power imbalance of the initial doctor-patient relationship which is likely to continue into the relationship between a doctor and his or her former patient, can also affect the patient's ability to consent. ${ }^{1}$ Feldman-Summers states, "even if consent can be given, exploitation can nevertheless be argued if the fiduciary has acquired information about the client's vulnerabilities that otherwise would remain concealed." ${ }^{\prime 39}$ Other arguments which question the former patient's ability to freely consent revolve around the patient's autonomous choice. Autonomous choice requires the patient to be competent and be provided with all relevant information to decide 
on a course of action, while not acting under any form of coercion. Simon argues that the provision of such information rarely, if ever, occurs. ${ }^{40}$ Coercion can arise from imposed restraints on any or all three types of autonomy: autonomy of thought, autonomy of will, and autonomy of action. ${ }^{41}$ Hall argues the persistence of transference can exert a coercive effect on one's autonomy of thought and/or will. ${ }^{1}$

In vignette 9, where the context of the doctor-patient relationship is in the general practice setting, Brody argues that a distinguishing characteristic of general practice ethics is the longitudinal relationship which develops between doctor and patient. ${ }^{42}$ This "relational ethic" is grounded in the goal of enhancing patient autonomy by, and through this relationship. From both these arguments it can be seen that attention to relationship is particularly important when considering general practice ethics. Hall argues that general practice has a particular duty to foster the autonomy of the patient and that a general practitioner's actions should be evaluated in the light of this duty. Sexual misconduct with a former patient does not foster patient autonomy and therefore a doctor participating in such a relationship is breaching this duty. ${ }^{1}$ The longitudinal relationship between the doctor and the patient in vignette 9 would make it difficult for the doctor to argue that there was minimal potential for transference-counter-transference to arise. It would also be difficult to argue that there was equality of power in a relationship arising from the original doctor-patient one. From both these perspectives the former patient would be extremely unlikely to be in a position to exercise true autonomy and choice when entering into a sexual relationship with the doctor.

This paper has implications for the future planning of ethics teaching in the Glasgow curriculum. Teaching on the subject of sexual or improper relationships between doctors and patients, including relationships with former patients requires to be made explicit. Case based teaching would fit in with the ethos of the problem based, integrated medical curriculum. Such teaching may help reduce the numbers of doctors entering such relationships in the future.

\section{CONTRIBUTORS}

JG conceived and designed the study, collected data, supervised data analysis, and wrote the paper. JM was involved in the conception and design of the study, its ongoing management, analysis of data, and contributed to the writing of the paper. LS was involved in the conception and design of the study and contributed to the writing of the paper.

\section{Authors' affiliations}

J Goldie, Department of General Practice, University of Glasgow, Glasgow, Scotland, UK

L Schwartz, Department of Clinical Epidemiology and Biostatistics, McMaster University, Hamilton, Ontario, Canada

J Morrison, Department of General Practice, University of Glasgow, Glasgow, Scotland, UK

This study was internally funded by the Department of General Practice, Glasgow University.

\section{REFERENCES}

1 Hall K. Sexualization of the doctor-patient relationship: is it ever ethically permissible? Fam Pract 2001;18:511-15.

2 Dehlendorf CE, Wolfe SM. Physicians disciplined for sex-related offenses. JAMA 1998;279:1883-8.

3 Council on Ethical and Judicial Affairs, American Medical Association. Code of Medical Ethics: Opinions with Annotations. Chicago, IL: American Medical Association, 1996-1997.

4 General Medical Council. Good Medical Practice, 3rd edn. London: General Medical Council, 2001

5 Searight HR, Campbell DC. Physician-patient sexual contact: ethical and legal issues and clinical guidelines. J Fam Pract 1993;36:647-53.
6 Thomson AN, White GE. Attitudes toward sexual contact between general practitioners and their patients. N Z Med J 1995; 108:247-9.

7 Lamont JA, Woodward C. Patient-physician sexual involvement: a Canadian survey of obstetricians-gynaecologists. CMAJ 1994;150:1433-9.

8 Ovens HJ, Permaul-Woods JA. Emergency physicians and sexual involvement with patients: an Ontario survey. CMAJ 1997; 157:663-9.

9 Bayer T, Coverdale J, Chiang E. A national survey of physicians' behaviours regarding sexual contact with patients. South Med J 1996;89:977-82.

10 Donaldson LJ. Doctors with problems in an NHS workforce. BMJ 1994;308:1277-82

11 Morrison J, Wickersham P. Physicians disciplined by a state medical board JAMA 1998;279:1889-93.

12 Enbom JA, Thomas CD. Evaluation of sexual misconduct complaints: the Oregon board of medical examiners, 1991 to 1995. Am J Obstet Gynaecol 1997; 176:1340-8.

13 Kardener SH, Fuller M, Mensh IN. A survey of physicians' attitudes and practices regarding erotic and non-erotic contact with patients. Am J Psychiatry 1973; 130:1077-81.

14 Fahy T, Fisher N. Sexual contact between doctors and patients almost always harmful. BMJ 1992;304:1519-20.

15 Dreiblatt IS. Health care providers and sexual misconduct. Federal Bull 1992;79:8-14.

16 Simon RJ. Therapist-patient sex. From boundary violations to sexual misconduct. Psychiatr Clin North Am 1999;22:31-7.

17 Gartrell NK, Milliken N, Goodsen WH, et al. Physician-patient sexual contact. Prevalence and problems. West J Med 1992;157:139-43.

18 Goldie J, Schwartz L, McConnachie A, et al. Impact of a new course on students' potential behaviour on encountering ethical dilemmas. Med Educ 2001;35:295-32

19 Goldie J, Schwartz L, McConnachie A, et al. The impact of three years ethics teaching, in an integrated curriculum, on students' proposed behaviour on meeting ethical dilemmas. Med Educ 2002;36:489-97.

20 Goldie J, Schwartz L, McConnachie A, et al. The impact of a modern medical curriculum on students' proposed behaviour on meeting ethical dilemmas. Med Educ 2004 (in press).

21 Huberman AM, Miles MB. Data management and analysis methods. In: Denzin NK, Lincoln YS, eds. Handbook of qualitative research. Thousand Oaks, CA: Sage, 1994:428-44.

22 Goldie J, Schwartz L, McConnachie A, et al. Students' attitudes and potential behaviour with regard to whistle blowing as they pass through a modern medical curriculum. Med Educ 2003;37:368-75.

23 Goldie J, Schwartz L, Morrison J. Students' attitudes and potential behaviour to a competent patient's request for withdrawal of treatment as they pass through a modern medical curriculum. J Med Ethics 2004;30:371-6.

24 Cohen L, Manion L, Morrison K. Research Methods in Education, 5th edn. London: Routledge Falmer 2000

25 Hafferty FW, Franks R. The hidden curriculum, ethics teaching and the structure of medical education. Acad Med 1994;64:861-71

26 Consensus Statement-Teaching medical ethics and law within medical education: a model for the UK core curriculum. J Med Ethics 1998;24:188-92.

27 General Medical Council. Duties of the Doctor, London, GMC, 1995

28 Goldie J. Review of ethics curricula in undergraduate medical education. Med Educ 2000;34:108-19.

29 McAlpine H, Kristianson L, Poroch D. Development and testing of the ethical reasoning tool (ERT): an instrument to measure the ethical reasoning of nurses. $J$ Adv Nurs 1997;25:1151-61

30 Schwartz LJ, Morrison J, Sullivan F. Rationing decisions: from diversity to consensus. Health Care Anal 1999;7:195-205.

31 American Psychiatric Association. The Principles of Medical Ethics with Annotations Especially Applicable to Psychiatry. Washington, DC: American Psychiatric Association, 1993.

32 Council on Ethical and Judicial Affairs, American Medical Association. Sexual misconduct in the practice of medicine. JAMA 1991;266:2741-5.

33 New Zealand Medical Council. Statement on Sexual Abuse in the DoctorPatient Relationship. Wellington: New Zealand Medical Council, 1994.

34 New Zealand Medical Council. Policy Statement on Sexual Relationships with Former Patients. Wellington: New Zealand Medical Council, 1996.

35 Epstein RS. Keeping Boundaries: Maintaining Safety and Integrity in the Psychotherapeutic Process. Washington, DC: American Psychiatric Press, 1994:15-34

36 Guntheil TG, Gabbard GO. The concept of boundaries in clinical practice: theoretical and risk-management dimensions. Am J Psychiatry 1993; 150:188-96

37 Zelas K. Sex and the doctor-patient relationship. N Z Med J 1997; 1 10:60-2

38 Gabbard GO, Pope KS. Sexual intimacies after termination: clinical, ethical and legal arguments. In: Gabbard GO, eds. Sexual Exploitation in Professional Relationships. Washington, DC: American Psychiatric Press, 1989:115-27.

39 Feldman-Summers S. Sexual contact in fiduciary relationships. In: Gabbard GO, eds. Sexual Exploitation in Professional Relationships. Washington, DC: American Psychiatric Press, 1989:193-209.

40 Simon RI. Transference in therapist-patient sex: the illusion of patien improvement and consent. Part 2. Psychiatr Ann 1994;24:561-5.

41 Gillon R. Autonomy and the principle of respect for autonomy. BM 1985;290:1806-8.

42 Brody H. Stories of Sickness. New Haven, CT: Yale University Press, 1987:171-81. 